\title{
Climatology of $\mathrm{Vb}$ cyclones, physical mechanisms and their impact on extreme precipitation over Central Europe
}

\author{
M. Messmer ${ }^{1,2}$, J. J. Gómez-Navarro ${ }^{1,2}$, and C. C. Raible ${ }^{1,2}$ \\ ${ }^{1}$ Climate and Environmental Physics, Physics Institute, University of Bern, Bern, Switzerland \\ ${ }^{2}$ Oeschger Centre for Climate Change Research, University of Bern, Bern, Switzerland
}

Correspondence to: M. Messmer (messmer@climate.unibe.ch)

Received: 18 March 2015 - Published in Earth Syst. Dynam. Discuss.: 4 May 2015

Revised: 14 July 2015 - Accepted: 8 August 2015 - Published: 1 September 2015

\begin{abstract}
Cyclones, which develop over the western Mediterranean and move northeastward are a major source of extreme weather and known to be responsible for heavy precipitation over the northern side of the Alpine range and Central Europe. As the relevant processes triggering these so-called $\mathrm{Vb}$ events and their impact on extreme precipitation are not yet fully understood, this study focuses on gaining insight into the dynamics of past events. For this, a cyclone detection and tracking tool is applied to the ERA-Interim reanalysis (19792013) to identify prominent Vb situations. Precipitation in the ERA-Interim and the E-OBS data sets is used to evaluate case-to-case precipitation amounts and to assess consistency between the two data sets. Both data sets exhibit high variability in precipitation amounts among different $\mathrm{Vb}$ events. While only $23 \%$ of all $\mathrm{Vb}$ events are associated with extreme precipitation, around $15 \%$ of all extreme precipitation days (99 percentile) over the northern Alpine region and Central Europe are induced by Vb events, although $\mathrm{Vb}$ cyclones are rare events (2.3 per year). To obtain a better understanding of the variability within $\mathrm{Vb}$ events, the analysis of the 10 heaviest and lowest precipitation $\mathrm{Vb}$ events reveals noticeable differences in the state of the atmosphere. These differences are most pronounced in the geopotential height and potential vorticity field, indicating a much stronger cyclone for heavy precipitation events. The related differences in wind direction are responsible for the moisture transport around the Alps and the orographical lifting along the northern slopes of the Alps. These effects are the main reasons for a disastrous outcome of $\mathrm{Vb}$ events, and consequently are absent in the $\mathrm{Vb}$ events associated with low precipitation. Hence, our results point out that heavy precipitation related to $\mathrm{Vb}$ events is mainly related to large-scale dynamics rather than to thermodynamic processes.
\end{abstract}

\section{Introduction}

High-impact weather events may have dramatic impacts on society, being a problem that could be potentially enhanced under a changing climate (IPCC-SREX, 2012). Such events not only lead to great economical damage, but also to personal damage (Kron et al., 2012; Held et al., 2013; Donat et al., 2011). Tropical but also extra-tropical cyclones can certainly be classified as high-impact weather events, as they are associated with extremely strong winds and heavy precipitation that eventually can lead to floodings (Fink et al., 2012; Raible, 2007; Stucki et al., 2014). In Central Europe, and more precisely in the northern Alpine region, a source of high-impact events is associated with the occurrence of
$\mathrm{Vb}$ cyclones. Such a type of cyclone was first mentioned by Köppen (1881), and later defined by Van Bebber (1891) in a cyclone classification based on its characteristic pathway (Fig. 1). The categories were labelled according to Roman numeration from one to five. The $\mathrm{Vb}$ track (a subcategory within the fifth category, and the only one still in use) is associated with extreme precipitation and flash floods over Germany, Austria, Switzerland, the Czech Republic and Poland. The origin of $\mathrm{Vb}$ cyclones is either the Bay of Biscay, the Balearic Sea or the Ligurian Sea, where moisture uptake occurs. The cyclone moves eastward via Italy and the Adriatic Sea, before it turns northward to the Black Sea or Saint Petersburg. Along this track, orographically induced rainfall 


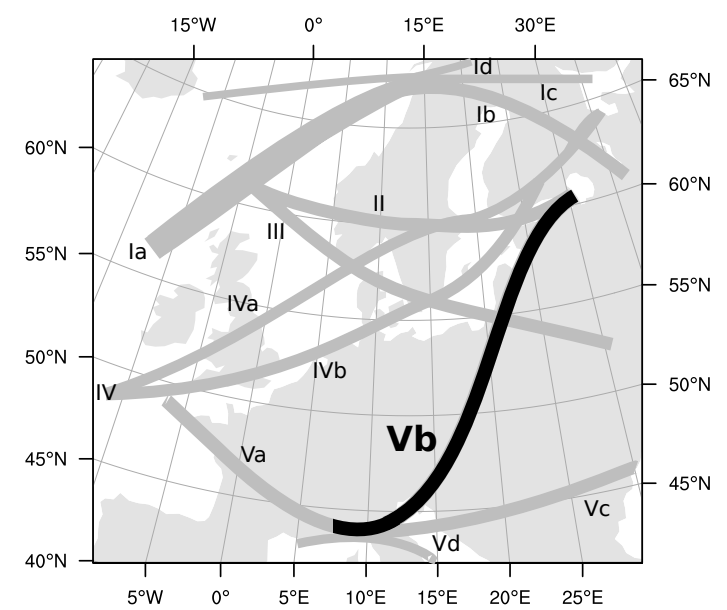

Figure 1. Trajectories of the barometric minima between 18761880 , as defined by W. J. van Bebber in 1981. The trajectory that defines $\mathrm{Vb}$ cyclones is highlighted in black.

takes place on the northern side of the Alps and its foothills. Note that a $\mathrm{Vb}$ cyclone is normally not associated with heavy precipitation events on the southern slope of the Alps. Heavy precipitation events on the southern side of the Alps can already be triggered by deep upper-level troughs over the Western Mediterranean and by Genova cyclogenesis (Martius et al., 2006; Winschall et al., 2012; Pinto et al., 2013). Hereinafter the expression $\mathrm{Vb}$ cyclone is used for cyclones that follow van Bebber's track.

Despite the destructive potential of $\mathrm{Vb}$ cyclones, literature provides only little information about its characterisation. Most studies on $\mathrm{Vb}$ cyclones focus on case studies. For instance the one-in-a-century flood in August 2002, induced by a $\mathrm{Vb}$ cyclone, has been analysed extensively (Ulbrich et al., 2003a, b; Grazzini and van der Grijn, 2002; Stohl and James, 2004; James et al., 2004; Kaspar and Müller, 2008). A main focus in these studies is the moisture source. Although the Mediterranean Sea is an important source for precipitable water, other studies suggested that the evaporation from land contributes to the precipitation amounts (Ulbrich et al., 2003a; Stohl and James, 2004; Sodemann et al., 2009). Additionally, the Atlantic Ocean and long-range advection of moisture cannot be despised, as demonstrated by Sodemann et al. (2009) using a tracer for water vapour. Another focal point is set on the synoptic-scale conditions leading to the extreme event in August 2002 (Ulbrich et al., 2003b; Grazzini and van der Grijn, 2002). Ulbrich et al. (2003b) suggested a positive interference of several factors that occurred in August 2002. These factors include advection of humidity, a quasi-stationary tropospheric trough, inducing upper-level divergence, and orographic lifting of the surface low. Grazzini and van der Grijn (2002) concluded that the anomalous large-scale situation in the summer of 2002 and the associated increased cyclone-activity is the main reason for the devastating floods in August 2002. Other Vb cyclones that appear as case studies in literature is cyclone "Axel", in July 2001, which is related to the Vistula flood (Kundzewicz et al., 2005). More important for Switzerland is the Vb cyclone in August 2005, which led to a very severe flood on the northern flanks of the Alps (Beniston, 2006). The author found that the peak rainfall occurs in August, and is due to a combination of warm ground surfaces and moisture convergence into the Alpine region. Another event happening in June 2013 is associated with cyclones that are nonstandard $\mathrm{Vb}$ systems, according to their paths, but nevertheless caused floods affecting the Danube and Elbe catchment (Grams et al., 2014). The authors recognised equatorward ascending warm conveyor belts as key processes for the heavy precipitation, which are fed by evapotranspiration from soil moisture.

Fewer studies go beyond case studies and analyse a $\mathrm{Vb}$ cyclone climatology. Hofstätter and Chimani (2012) provided an objective catalogue of $\mathrm{Vb}$ cyclones, which allowed the authors to infer that these are only rare events (3.5/year) with a peak occurrence during April. Nissen et al. (2013) focused on the summer half year of a future climate. They projected a decrease in the total number of $\mathrm{Vb}$ cyclones, although their related mean precipitation increases. An extended study, considering the last 500 years of flood history, only found a weak relation between $\mathrm{Vb}$ pathways and flood occurrence (Mudelsee et al., 2004). Although there is only little literature specifically focused on climatological $\mathrm{Vb}$ cyclone characteristics, there are several studies devoted to the cyclones in the Mediterranean region, a more general category to which the Vb cyclones belong to. Trigo et al. (1999) performed an objective climatology of cyclones in the Mediterranean region, concluding that the Genoa region, which is also the main origin of $\mathrm{Vb}$ cyclones, generates most of the cyclones in the Mediterranean region. The authors also stated that topography-controlled cyclogenesis regions account for the most intense events. Fricke and Kaminski (2002) showed that the period from 1881 to 2001 , which includes the most extreme precipitation events, reveals a more frequent appearance of the weather pattern trough over Middle Europe. This pattern also encloses the $\mathrm{Vb}$ cyclones. Sodemann and Zubler (2010) analysed a similar, although shorter period of time (1995-2002), focusing on precipitation over the Alps. They determined a seasonal change in the moisture source for both sides of the Alps, i.e., the Mediterranean Sea and the Atlantic Ocean are the major sources in winter for the southern and northern slopes of the Alps, respectively, whereas soil moisture content is predominant in summer. Hence, $\mathrm{Vb}$ cyclones show all the prerequisites needed to trigger highimpact weather events.

Cyclones in the Mediterranean region are frequently analysed under future climate change, as the Mediterranean Basin is a key hotspot for societal vulnerability (Giorgi, 2006; IPCC-AR4, 2007). Unfortunately, there is still no clear agreement on the trend in cyclone numbers in a future climate. Some studies concluded that there will be a general 
decrease in the number of cyclones during the entire year (Lionello et al., 2002; Nissen et al., 2014) or just in winter (Pinto et al., 2006; Raible et al., 2010), due to either a polar shift of cyclones, a positive shift of the NAO, changes in baroclinicity or static stability. However, other analyses reported an increase in the total number of cyclones over the Mediterranean (Muskulus and Jacob, 2005; Nissen et al., 2014). The studies also disagreed with respect to extreme events, where Lionello et al. (2002) and Pinto et al. (2006) found an increase, whereas Muskulus and Jacob (2005) and Nissen et al. (2014) found a decrease in extreme cyclones in the Mediterranean. Additionally, Muskulus and Jacob (2005) indicated no significant changes concerning the track properties and precipitation. This is in contrast to Gao et al. (2006), who found a pronounced decrease, especially in summer precipitation, due to an intensified anticyclonic ridge. Nonetheless an increase in precipitation events, especially over and around the Alpine region, can be expected especially in winter according to the study of Gao et al. (2006) due to the fine scale structures in the Alps. Furthermore Zappa et al. (2014) identified two opposing factors in the Mediterranean region, which might be responsible for the large inter-model spread of the CMIP5 models. On one hand these are a general increase in atmospheric moisture content and thus, an increased cyclone precipitation intensity. On the other hand Zappa et al. (2014) found a reduction in precipitation intensity due to a dynamical weakening of the cyclones. The lack of consistency that emerges from these studies illustrates the difficulties involved in climate projections, and point out that a deeper process understanding is important to reduce uncertainties.

As outlined above, only basic climatologies of $\mathrm{Vb}$ cyclones in the past (Hofstätter and Chimani, 2012) and the future (Nissen et al., 2013) have been performed so far. However, a comprehensive analysis concerning the triggering mechanisms driving the extreme precipitation associated with $\mathrm{Vb}$ cyclones is still missing. Thus, in this study we provide a climatology of $\mathrm{Vb}$ cyclones and also explore the physical mechanisms that impact precipitation amounts of Vb cyclones. The climatology is performed for a $35-y r$ period using the ERA-Interim reanalysis, whereas the physical mechanisms are studied in more detail for $\mathrm{Vb}$ cyclone subcategories.

The structure of this paper is as follows: Sect. 2 provides an overview of the data sets and methods used in the study. Section 3 describes the basic climatology of $\mathrm{Vb}$ cyclones, gives insight into the $\mathrm{Vb}$ cyclone variability, and investigates their underlying physical mechanisms. Finally, Sect. 4 provides a summary and discussion of the results, presenting also a short outlook.

\section{Data and methods}

\subsection{Reanalysis and observational data sets}

This study is based on ERA-Interim, a global atmospheric reanalysis data set (Dee et al., 2011) produced by the European Centre for Medium-Range Weather Forecasts (ECMWF). ERA-Interim provides 6-hourly estimates of three-dimensional meteorological parameters and 3-hourly estimates for surface variables for the time period between 1979 to present. The ERA-Interim data set is generated by running the 2006 version of the Integrated Forecast System model of the ECMWF with a resolution of T255 (approximately $80 \mathrm{~km}$ ) and 60 vertical levels up to $0.1 \mathrm{~Pa}$. The system assimilates observational data with a 4-dimensional variational analysis (4D-Var) in a $12 \mathrm{~h}$ analysis window. A number of observational data sets are assimilated in the final product ranging from satellite data to surface pressure observations and radiosonde profiles (see Sect. 4 in Dee et al., 2011).

In this study we analyse $\mathrm{Vb}$ cyclones for the 35-year period 1979-2013 at 6-hourly resolution. To facilitate the comparison, the 3-hourly forecasted precipitation data are accumulated to 6-hourly data. Furthermore, a vertical integration of moisture in the atmosphere is computed to obtain the total amount of precipitable water. As precipitation data in ERAInterim are predicted using a forecast model, they are subject to spin-up and spin-down effects that need to be kept in mind (Dee et al., 2011).

Since some important results in this study are based on precipitation amounts, and given that ERA-Interim reanalysis suffers from the aforementioned spin-up and spin-down effects, the precipitation data are compared to the purely observational gridded product E-OBS (Haylock et al., 2008). The E-OBS data are based on weather station data and are interpolated to a $25 \mathrm{~km}$ grid. It is a European land-only, daily, gridded data set. Several variables are available: precipitation, sea level pressure and mean, minimum and maximum temperature for the period 1950 to 2013 (Haylock et al., 2008). As this data set is based on observations only, there are a number of limitations that need to be mentioned. On the one hand the observations show several inhomogeneities in space and time that populate observational products with uncertainties rendering them mutually inconstant even in areas properly covered by observations (Gómez-Navarro et al., 2012). The spacial inhomogeneity is due to a different density of the observational network of each country, whereas the temporal heterogeneity is based on the varying number of stations maintained by the countries (Hofstra et al., 2009). On the other hand precipitation is especially affected by uncertainties over mountain areas, such as the Alps, our region of interest. Note that the uncertainties are maximal in the summer, as precipitation is driven by convection (Hofstra et al., 2009). This form of precipitation is very local, and thus difficult to capture with the sparse network covering the Alps (Hofstra et al., 2009). 


\subsection{Detection and tracking methods}

In this study we use a tool developed by Blender et al. (1997) that automatically detects and tracks all types of cyclones within a certain area. Thus, in a first step all cyclones that occur over Western and Central Europe during the 35-year time period are retained. Note that different tracking and detection methods identify comparable characteristics of midlatitude cyclones (Raible et al., 2008; Neu et al., 2013). For the Mediterranean, different methods show some disagreement in particular with respect to the identified number of cyclone, but agree in terms of location, annual cycle, and trends of cyclone tracks (Lionello et al., 2015). The technique has a number of free parameters that allow to adjust the search according to specific purposes. In our case, these parameters are fit to special characteristics of Mediterranean cyclones. In particular, since they develop as shallow low-level cyclones, weak gradients must be chosen in order to be able to detect these at the beginning of their life cycle.

Since the Alps introduce disturbances into the geopotential height field, and to remove small-scale and secondary low pressure centres, the input data $\mathrm{z} 850$ from ERA-Interim is previously low-pass filtered using a weighted average of $5 \times 5$ grid points prior to the analysis of the tracks. The weights are defined according to a Hann-window function. The $5 \times 5$ window has been chosen by analysing the robustness of the obtained trajectories after different window sizes are applied in the smoothing (not shown). Similarly, several levels of the geopotential height fields are tested within the detection and tracking technique, using finally the $850 \mathrm{hPa}$ level. The reason is on the one hand to have a balance between the shallow character of Mediterranean cyclones and therefore a level close to the ground. On the other hand, it is hardly possible to find meaningful tracks at the surface, as mountains introduce substantial artefacts into the geopotential height field that render the cyclone tracking more difficult. Tests with several levels and filters have shown that the prominent Vb cyclones (Alpine flood 2005, Elbe flood 2002, Axel 2001) can be identified in the $850 \mathrm{hPa}$ level in combination with a $5 \times 5$ grid point weighted average low-pass filter, so this is the configuration employed in the manuscript.

The position of the cyclones is identified by local minima in the geopotential height at $850 \mathrm{hPa}$ (z850), taking the eight neighbouring grid points into account. The minimum gradient around a cyclone centre in an area of $1000 \times 1000 \mathrm{~km}^{2}$ is used to focus on cyclones, thus filtering out polar and weak minima such as heat lows. For this study we applied a minimum gradient of $25 \mathrm{~m} / 1000 \mathrm{~km}$. Additionally, a maximum gradient of $50 \mathrm{~m} / 1000 \mathrm{~km}$ must be reached at least once during the life cycle of a cyclone. The minimum lifetime of each cyclone is set to $24 \mathrm{~h}$. The minima are combined by a next neighbourhood search within a distance of $1000 \mathrm{~km}$. This threshold is chosen as it resembles roughly the Rossby deformation radius.

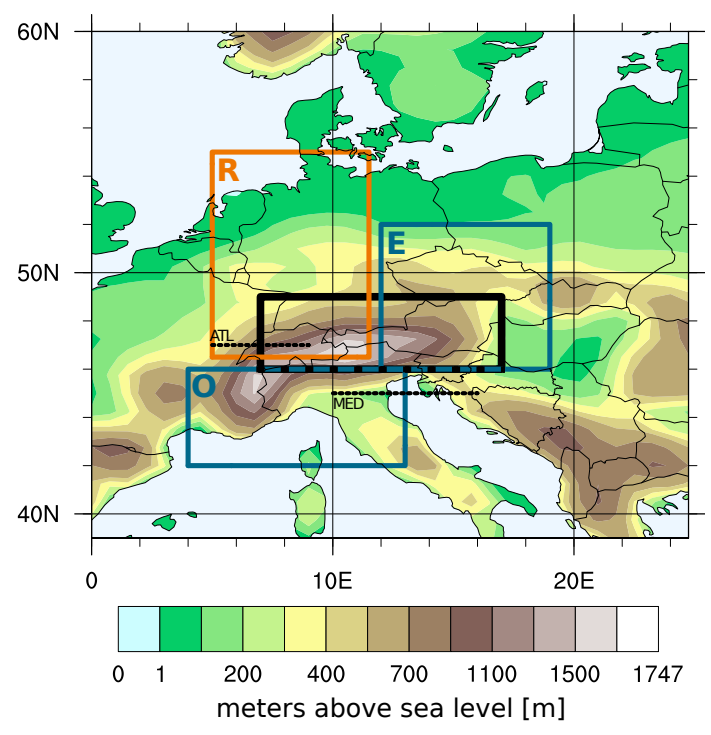

Figure 2. The three boxes used to automatically filter out the $\mathrm{Vb}$ cyclones from the total number of cyclones found by the tracking technique (Blender et al., 1997). O, E and R denote the origin, the end and the restriction box, respectively. The black box over the alpine region defines the area of interest for precipitation amounts. The two stippled black lines indicate the position of the two crosssections used to calculate the moisture flux. The topography corresponds to the one implemented in ERA-Interim.

As the tracking tool detects all cyclones, not only $\mathrm{Vb}$ cyclones, the output of this tool has to be further filtered. For this task, we define areas (boxes) where a potential $\mathrm{Vb}$ cyclone shall pass (or not pass) at least once in its lifetime in order to be retained. The origin box $\left(42-46^{\circ} \mathrm{N}, 4-13^{\circ} \mathrm{E}\right)$ accounts for the fact that $\mathrm{Vb}$ cyclones, per definition, either develop or intensify over the Mediterranean Sea close to Genoa, while the end box $\left(46-52^{\circ} \mathrm{N}, 12-19^{\circ} \mathrm{E}\right)$ assures the sudden turnaround northward at the eastern edge of the Alps. Note that the cyclone can leave the end box towards the east at the end of its life cycle. The purpose of the boxes is to guide the cyclones around the Alps. As soon as this task is fulfilled the cyclones can move freely. A third restrictive box $\left(46.5-55^{\circ} \mathrm{N}, 5-11.5^{\circ} \mathrm{E}\right)$ covering the Alps and the eastern part of Germany is introduced to avoid that cyclones stay at any time on the northern side of the Alps before they move around the Alpine range on its eastern side. These three boxes are displayed in Fig. 2 and are labelled with $\mathrm{O}$ for the origin, $\mathrm{E}$ for the end and R for the restriction box. Note that these simple criteria are similar to that described by Hofstätter and Chimani (2012).

\subsection{Composite analysis of midlatitude cyclones}

A prominent problem when analysing the structure and physical processes related to cyclones is that they do not occur at a fixed location, but they are moving objects. Hence, a simple temporal mean becomes misleading due to the different 
location of the storm. A simple approach to overcome this problem is to use a moving grid whose centre coincides with the storm at each time step. However, this still has a problem when the analysis is performed on a regular latitudelongitude grid (as is the case of ERA-Interim). This is so because the area of each grid box relative to the centre of the cyclone decreases with higher latitudes, so each grid point might be representative of a different area in different time steps if the storm moves northward. This is not a major problem in tropical cyclones, since the effect becomes insignificant near the equator, but it is a matter of concern in the midlatitudes, precisely where $\mathrm{Vb}$ cyclones evolve. Since this study aims at analysing temporal composites of several variables, or the most precipitation intense time step in different cyclones, this becomes a technical challenge that has to be addressed.

This study applies a composite tool based on the projection described by Bengtsson et al. (2007). The method works as follows. The variable of interest, defined on a latitudelongitude grid, is first remapped onto spherical coordinates in a $0.5^{\circ} \times 0.5^{\circ}$ resolution grid, where the cyclone's centre is set in the pole of the grid. This grid extends with a radius of $23^{\circ}$ around the cyclone's centre. Hereby, a spherical cap is obtained for each time step, which is always directed towards the north. Once the variable of interest is remapped onto this grid (which is different for each time step), all regular statistics can be calculated over this variable (means, maximum, etc.), and the results are fully comparable among different time steps and storms.

\subsection{Selecting the precipitation influencing time steps in the life cycle of $\mathrm{Vb}$ cyclones}

In the following analysis we focus on precipitation triggered by $\mathrm{Vb}$ cyclones. The area of interest for precipitation covers the northern slopes of the Alps, the southern part of Germany, Austria and the southern part of the Czech Republic. This area is depicted in Fig. 2 as a black rectangle. The beginning and the end of the tracks of the $\mathrm{Vb}$ cyclones can be located, e.g. in the Atlantic Ocean and far up in the north of Poland or even Russia, respectively. If the centre of the cyclone is placed that far away from the black box described above it must be assumed that the cyclone no longer influences the falling precipitation in this area. Furthermore, it is more likely that a different weather feature, like a frontal system, disconnected from the $\mathrm{Vb}$ cyclone, produces precipitation in that area. To omit this we make use of the composite tool described in Sect. 2.3 in a slightly adapted way, such that only time steps are included in the analysis which exhibit a cyclone centre close enough to the region of interest. Thus, the radius of the grid area around the cyclone's centre in the composite tool, which is influenced by the cyclone, depends on the gradient of the cyclone, and thus on its intensity. Hence, $\mathrm{Vb}$ cyclones ascribing a gradient within plus or minus 1 standard deviation obtain a radius of $6^{\circ}$. Gradients that exceed (fall behind) one standard deviation, 75 (25) percentile or 95 (5) percentile obtain a radius expansion (decrease) of $0.5,1$ or $1.5^{\circ}$, respectively. Only if this radius is able to reach the precipitation box depicted in Fig. 2, the time step is considered as precipitation contributing. Note that the flexible radius in combination with the composite tool is only used to define the precipitation influencing time steps. For all other variables the composite tool is applied with a fixed radius of $23^{\circ}$ as described in Sect. 2.3.

\section{Results}

\subsection{Basic climatology of $\mathrm{Vb}$ cyclones}

$\mathrm{Vb}$ cyclones are relatively rare events compared to the frequency of cyclones detected over the Mediterranean and Europe. Applying the tracking approach of Blender et al. (1997) to the smoothed z850 surface, 3448 cyclones are detected over Europe between 1979 and 2013. After filtering out the cyclones with the boxes described in Sect. 2.2, a total of only 82 cyclones is classified as $\mathrm{Vb}$ cyclones, i.e. only $2.4 \%$ of all cyclones in Western and Central Europe. Due to their rareness, the average appearance of $\mathrm{Vb}$ cyclones per year is 2.3 , with a mean duration of 3.1 days. Still, the occurrence of these events is irregularly distributed over the 35year period (for instance up to five $\mathrm{Vb}$ cyclones are tracked in 1979 and 1984, while none is found in the years 1989, 1993 and 2011). However, considering ERA-Interim (E-OBS) data set in this period of time the rare $\mathrm{Vb}$ events are responsible for almost $15 \%(14 \%)$ of extreme precipitation days in the northern Alpine region and Central Europe. Here, extreme precipitation days are defined as exceedance of the 99 percentile. Hence, we note that even though $\mathrm{Vb}$ events are relatively rare, they have a great potential to trigger high-impact weather events.

Using a similar approach, Hofstätter and Chimani (2012) reported an annual average of $3.5 \mathrm{Vb}$ cyclones per year. The climatological probability of $\mathrm{Vb}$ cyclones to appear on any day is $3.8 \%$ in their analysis, compared to the $2.0 \%$ found in the present study. The potential reason for this discrepancy is that their method substantially differs from the one used here: different input data, tracking tool, and posterior filtering. Still, $62 \%$ of the $\mathrm{Vb}$ cyclones tracked in this study coincide with those found by Hofstätter and Chimani (2012), considering only the overlapping period from 1979 to 2002 of the two studies.

Beyond the irregular distribution of the $82 \mathrm{Vb}$ cyclones over the analysed period, they are also not evenly distributed within the annual cycle. Considering the standard seasons winter (December, January, February), spring (March, April, May), summer (June, July, August) and autumn (September, October, November) there are less Vb cyclones in winter than expected from a homogeneous distribution over the annual cycle ( $p$ level $<0.1$ ) and an excess in spring ( $p$ level $<0.05$ ). The fact that $\mathrm{Vb}$ cyclones emerge more frequently in spring 

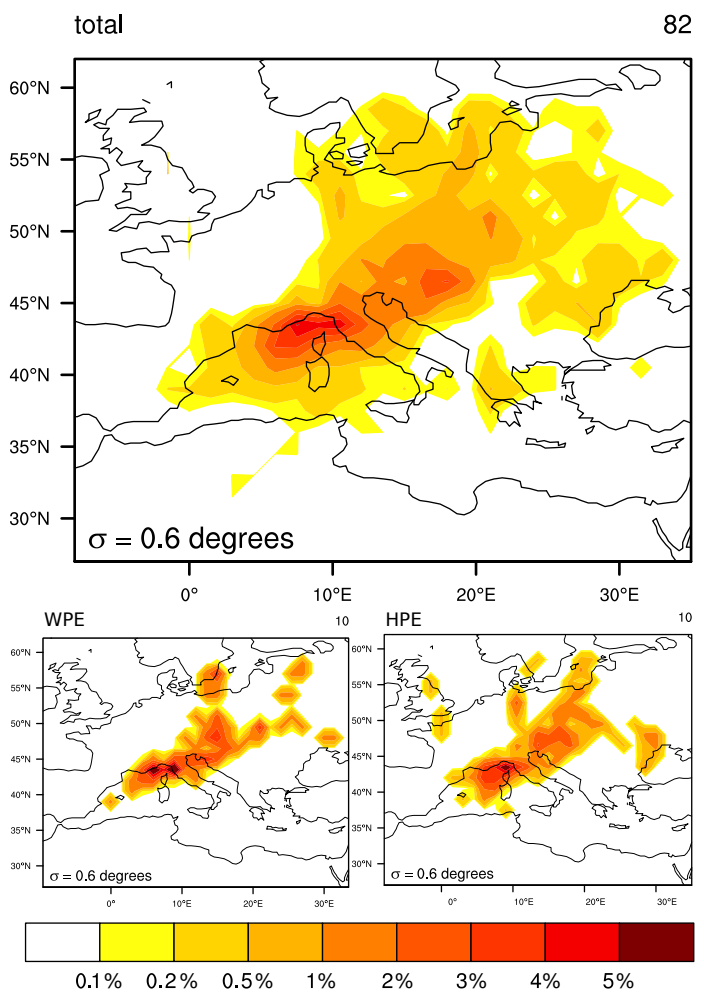

Figure 3. Probability density field of all detected Vb cyclone centres (top panel), of the heavy precipitation events (HPEs) (bottom left panel) and of the weak precipitation events (WPEs) (bottom right panel). The shading shows how probable it is that a Vb cyclone centre is located at the according grid point at any time step in the 1979-2013 period.

has already been pointed out by Van Bebber (1891) and confirmed by Hofstätter and Chimani (2012), which reported a maximum in April.

The $\mathrm{Vb}$ cyclones are also characterised by their trajectories. The probability density of all $\mathrm{Vb}$ cyclone centres is depicted in the upper panel of Fig. 3 and estimated using a Gaussian Kernel Density Estimator with a bandwidth of $0.6^{\circ}$. Thus, the shaded area indicates how likely it is that a $\mathrm{Vb}$ cyclone centre passes through this grid point at any time step. The density illustrates the most common pathways followed by $\mathrm{Vb}$ cyclones, and fits very well the track described by Van Bebber (1891), illustrating why this categorisation is still in use. As expected the Genoa region is most frequently passed by the cyclones, as this region coincides with the origin box. Even a rare $\mathrm{Vb}$ cyclone, which develops in the lee of the Atlas Mountains, is detected once. Note that the end of the $\mathrm{Vb}$ cyclone track is more diverse, given that the last time steps of the $\mathrm{Vb}$ cyclones are no longer bound to any box. The effect of the restriction box is clearly visible as a sharp bend of the orange-coloured contours at the western flanks of the Alps.
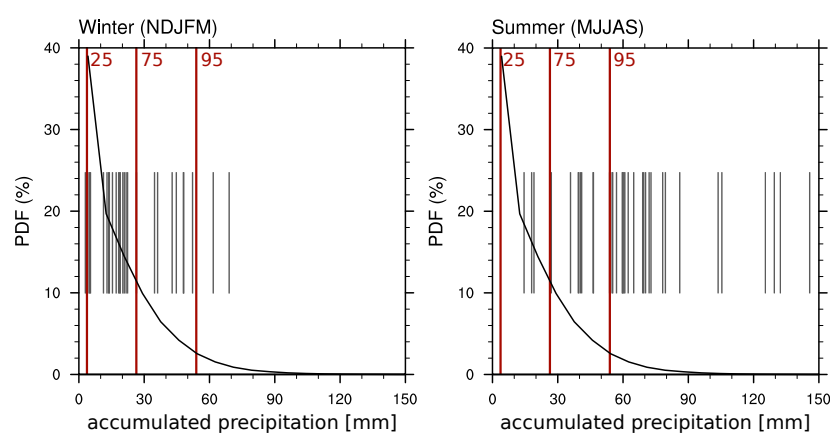

Figure 4. Probability density function of the accumulated precipitation from ERA-Interim of $\mathrm{Vb}$ events (black line) for extended winter (left panel) and extended summer (right panel). The red lines indicate the 25, 75 and 95 percentile from left to right. The vertical, black lines indicate the accumulated precipitation of all $\mathrm{Vb}$ cyclones occurring during each season, respectively.

\subsection{Variability within $\mathrm{Vb}$ cyclones}

In this section we build upon the analysis of $\mathrm{Vb}$ cyclone characteristics focusing on remarkable differences between these events, particularly with respect to precipitation. Thereby, $\mathrm{Vb}$ events are classified by using a precipitation criterion. For this, the mean precipitation over a box covering the Alpine region is calculated for each time step. The box is depicted in Fig. 2 as a black rectangle. In the following, the precipitation of the precipitation contributing time steps (as described in Sect. 2.4) is accumulated over each $\mathrm{Vb}$ event. Note that this has the disadvantage that the accumulation period differs among various $\mathrm{Vb}$ cyclones, which has to be taken into account in the analysis hereafter.

To compare the precipitation triggered by $\mathrm{Vb}$ cyclones to regular precipitation days, the distribution of such precipitation needs to be estimated. As the $\mathrm{Vb}$ cyclone duration differs from one another, the estimation of the precipitation distribution becomes challenging. Hence, a bootstrap method is applied to estimate such precipitation distribution over this particular box that has to mimic the real distribution of $\mathrm{Vb}$ cyclone duration. The estimation is based on 3 million bootstrap samples of observed precipitation accumulated during a period whose length is selected randomly according to the observed distribution of length of $\mathrm{Vb}$ cyclones. The same method is applied to the ERA-Interim and daily E-OBS data set to confirm consistency between observational data and forecasted reanalysis data. Figure 4 displays the estimated distribution of precipitation in the box covering the Alpine region for ERA-Interim. Using ERA-Interim (E-OBS, not shown) data set, only two (none) of the $\mathrm{Vb}$ cyclones exceed the 95 percentile in winter, whereas in summer, 24 (19) $\mathrm{Vb}$ cyclones produce extreme precipitation over the region of interest. Note that there is a wide variability in accumulated summer precipitation within $\mathrm{Vb}$ cyclones, ranging between almost no precipitation and extreme events. Furthermore, 

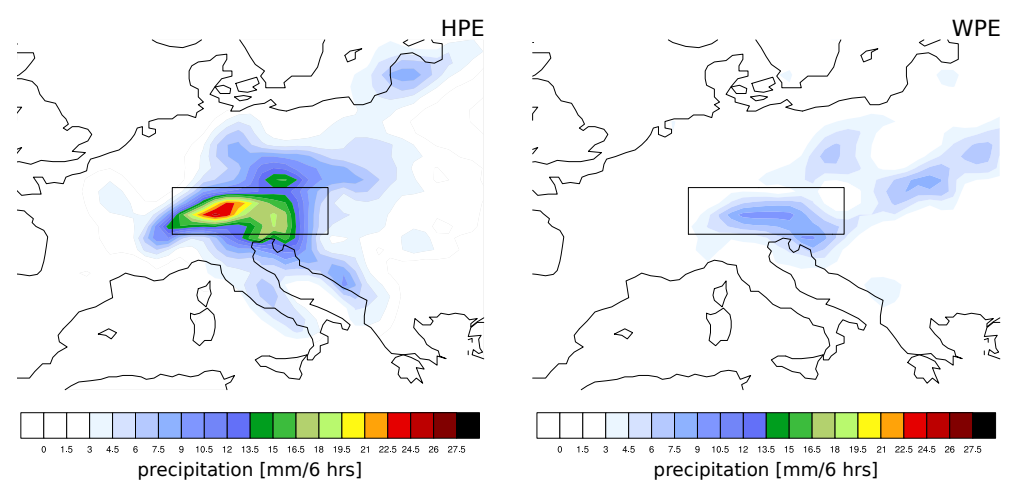

Figure 5. Average precipitation during the time step with maximum precipitation for the $10 \mathrm{HPEs}$ (left panel) and the $10 \mathrm{WPEs}$ (right panel). The black box indicates the precipitation region of interest, depicted also in Fig. 2 as a black rectangle.

most of the winter events show a narrow variability. For consistency reasons and the sake of brevity only the results for ERA-Interim data are shown hereafter, although it has to be noted that the results for the E-OBS data set resemble the findings based on ERA-Interim discussed here in more detail. The striking difference between summer and winter is most probably due to the effect of the Clausius-Claperyon equation, which relates air temperature to its ability to carry water vapour.

To gain further insight in the characteristics of $\mathrm{Vb}$ cyclones, those related to heavy precipitation events (HPE) and weak precipitation events (WPE) in the extended summer season are analysed in detail. Thereby, the 10 most extreme events with respect to precipitation are selected. Figure 5 displays a composite of the most intense precipitation time step of the 10 HPE on the left and WPE on the right. As expected, the HPEs generate much more precipitation and affect a wider area. Locally, the precipitation amounts are even doubled compared to the WPEs. More interesting is the fact that the HPEs composite shows a precipitation pattern that is expected from $\mathrm{Vb}$ events. The main precipitation falls on the northern flanks of the Alps and extends towards the east as far as the catchment of the river Elbe and Oder, which were the main contributors of the floods in August 2002 (U1brich et al., 2003a; Kundzewicz et al., 2005). In contrary the WPEs show maximum precipitation more to the east of the Alps. Additionally, there seems to be frontal behaviour that interferes with $\mathrm{Vb}$ cyclones in some of the WPEs which is illustrated by the long precipitation band in Eastern Europe. It is important to note that even though precipitation patterns are different, the associated PDFs of the trajectories of HPEs and WPEs, depicted in the lower panels of Fig. 3, do not show significant differences. Thus, the trajectory of the $\mathrm{Vb}$ cyclone does not seem to play an important role on deciding whether an event will cluster into the HPE or the WPE subcategories.

\subsection{Physical mechanisms driving $\mathrm{Vb}$ cyclones variability}

As precipitation amounts are linked to available moisture content in the atmosphere, it makes sense to investigate whether the state of the atmosphere plays a prominent role on the rainfall associated to a Vb cyclone (Stohl and James, 2004; Sodemann et al., 2009). The precipitable water at the most precipitation intense time step shows a much higher amount for the HPEs, than for WPEs (Fig. 6). Still, the differences around the centre of the cyclone are small compared to the high moisture band further off the centre. The moisture fluxes depicted in Fig. 6 imply that the major part of this moisture is transported straight to the northeast, and thus away from the northern Alpine region for the WPEs and the HPEs. Note that some of this precipitable water can lead to precipitation further north over, e.g. Eastern Germany. The additional precipitation in the northeast of the box can easily be detected in Fig. 5. This is especially true for the HPEs. Furthermore, the case-to-case variability in precipitable water is relatively large, and indeed some HPE cases contain even less precipitable water than certain WPEs. Hence, precipitable water in the atmosphere is not an unambiguous variable suitable to predict whether a $\mathrm{Vb}$ cyclone would potentially lead to severe precipitation.

A related variable that is in principle more accurate to characterise the differences observed between HPEs and WPEs is the moisture flux through certain latitude sections of interest. This allows testing the hypothesis generally assumed stating that $\mathrm{Vb}$ cyclones receive most of their precipitable water from the Mediterranean Sea. Therefore, a latitudinal section over the Adriatic Sea is selected as depicted in Fig. 2 with a stippled black line labelled MED. This section is chosen because it is located over a region of high vertical moisture transport. Results of the moisture flux through this section indicate however that no clear separation of the moisture flux across this line between the HPEs and WPEs is possible (left panel of Fig. 7). Thus, this criterion is not suitable to characterise the high-impact related Vb cyclones. Similarly, a second cross-section over France and Switzerland la- 

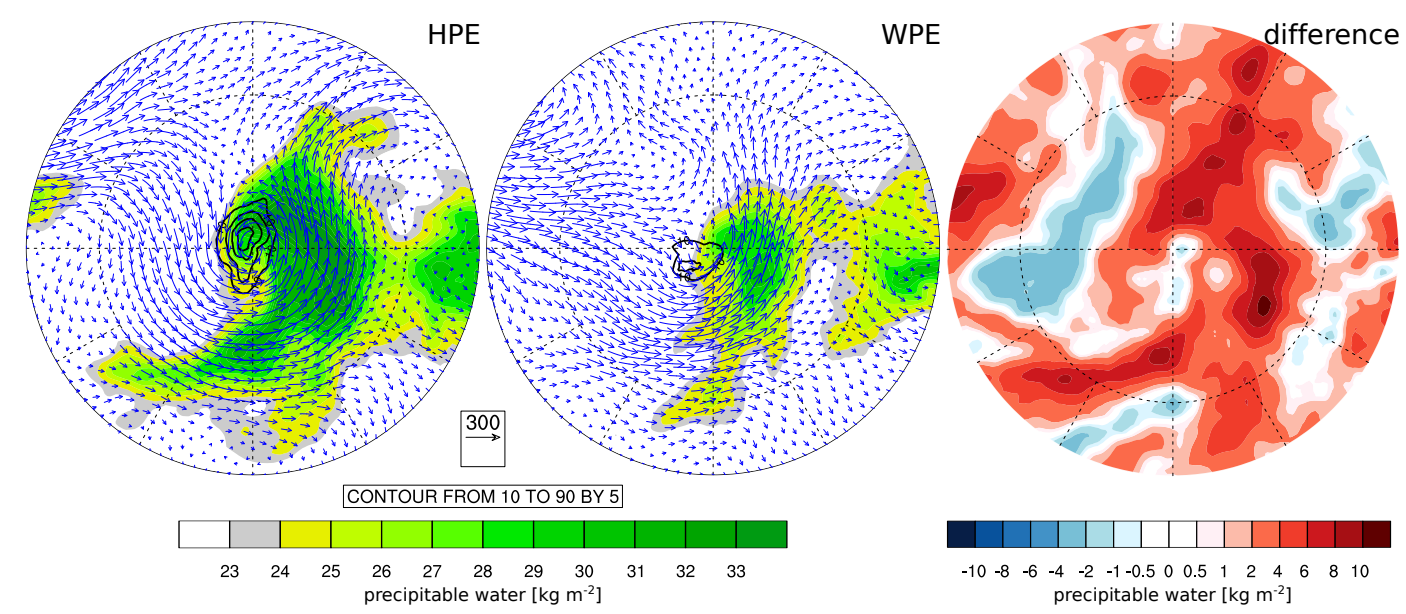

Figure 6. Composites of precipitable water content $\left[\mathrm{kg} \mathrm{m}^{-2}\right.$, shading] and precipitation amounts (black contours) for the HPEs (left panel) and for the WPEs (centre panel). Additionally the moisture flux is shown by arrows integrated over the vertical structure of the atmosphere (reference vector: $300 \mathrm{~kg} \mathrm{~m}^{-1} \mathrm{~s}^{-1}$ ). The time step with maximum precipitation is shown for all variables. The distance from the centre of the composite cyclone to the edge is $23^{\circ}$. The difference in precipitable water between HPEs and WPEs is shown (right panel).
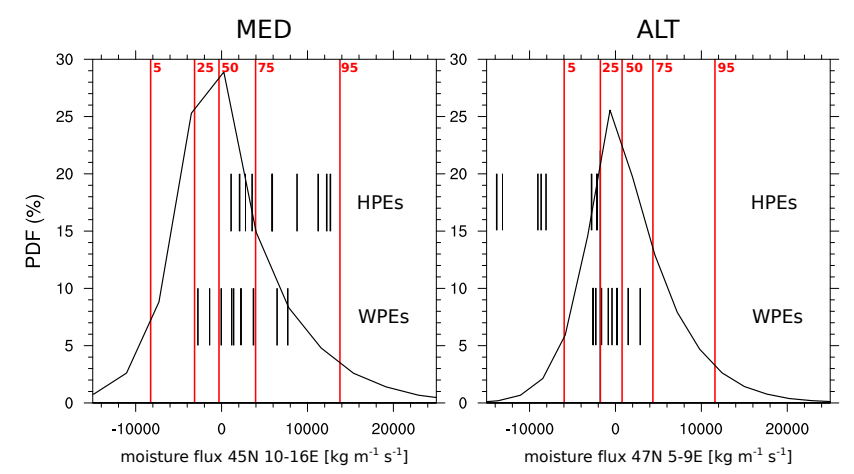

Figure 7. Probability density function of the accumulated moisture flux of all $\mathrm{Vb}$ events (black line). The vertical top (bottom) lines indicate the accumulated moisture flux of the HPEs (WPEs) through the stippled black lines depicted in Fig. 2 labelled with "MED" (left panel) and labelled with "ATL" (right panel). The red lines indicate the 5, 25, 50, 75 and 95 percentile from left to right.

belled ATL in Fig. 2 allows to analyse the southward moisture flux from the North Atlantic Ocean. As the right panel of Fig. 7 demonstrates, this cross-section enables a slightly clearer separation between HPEs and WPEs than the moisture fluxes across MED line. The increased transport of HPEs suggests that a large part of moisture is transported from the North Atlantic, instead of the Mediterranean Sea. Still, no clear separation between the HPEs and the WPEs is found, especially because it is very sensitive to the exact location of this cross-section (not shown). Hence, these results indicate that moisture variables alone do not allow explaining the different behaviour observed between HPEs and WPEs.

Since the thermodynamic state of the atmosphere cannot present a distinct explanation for the within- $\mathrm{Vb}$ variability, we turn our attention to the dynamical mechanisms. One rea-
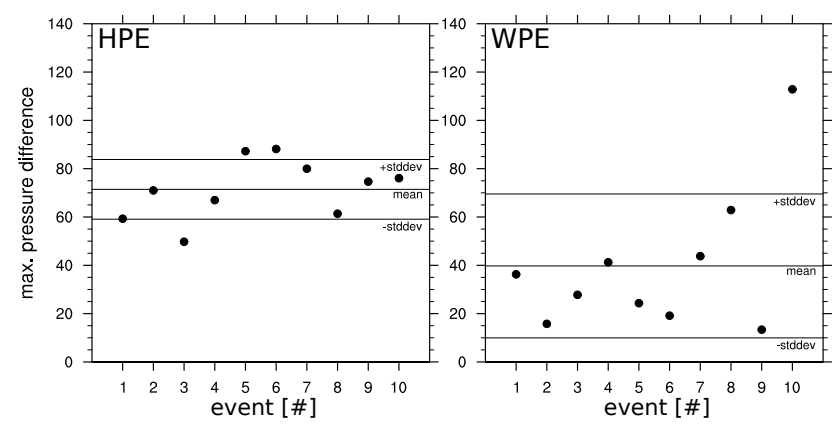

Figure 8. Difference between the minimum and maximum pressure during the entire life cycle for the HPEs (left panel) and WPEs (right panel). The events are sorted according to precipitation produced in the target area (Fig. 2), with \#1 being the most extreme precipitation event. The three horizontal black lines indicate the mean and the standard deviation, respectively.

son for the different amounts in precipitation between the HPE and WPE might be the speed of the cyclone. Fast moving Mediterranean cyclones may not be able to pump up as much water from the ocean than slow moving cyclones. Nevertheless a clear separation in cyclone propagation speed between the HPE and WPE is not successful. Reasons for the deviations in precipitation amounts and pattern among $\mathrm{Vb}$ cyclones are found more clearly in the geopotential height field. Figure 8 reveals that the WPEs overall show a smaller intensification rate than HPEs ( $p$ level $<0.01$ ). Further differences in the geopotential height are found in the spatial structure of the average state (Fig. 9). The HPEs and WPEs show similar features at first glance in the z850 field during the most precipitation intense time step. In both cases a low pressure area is localised in the centre of the storm. This is expected, as this is indeed the criterion used for the de- 

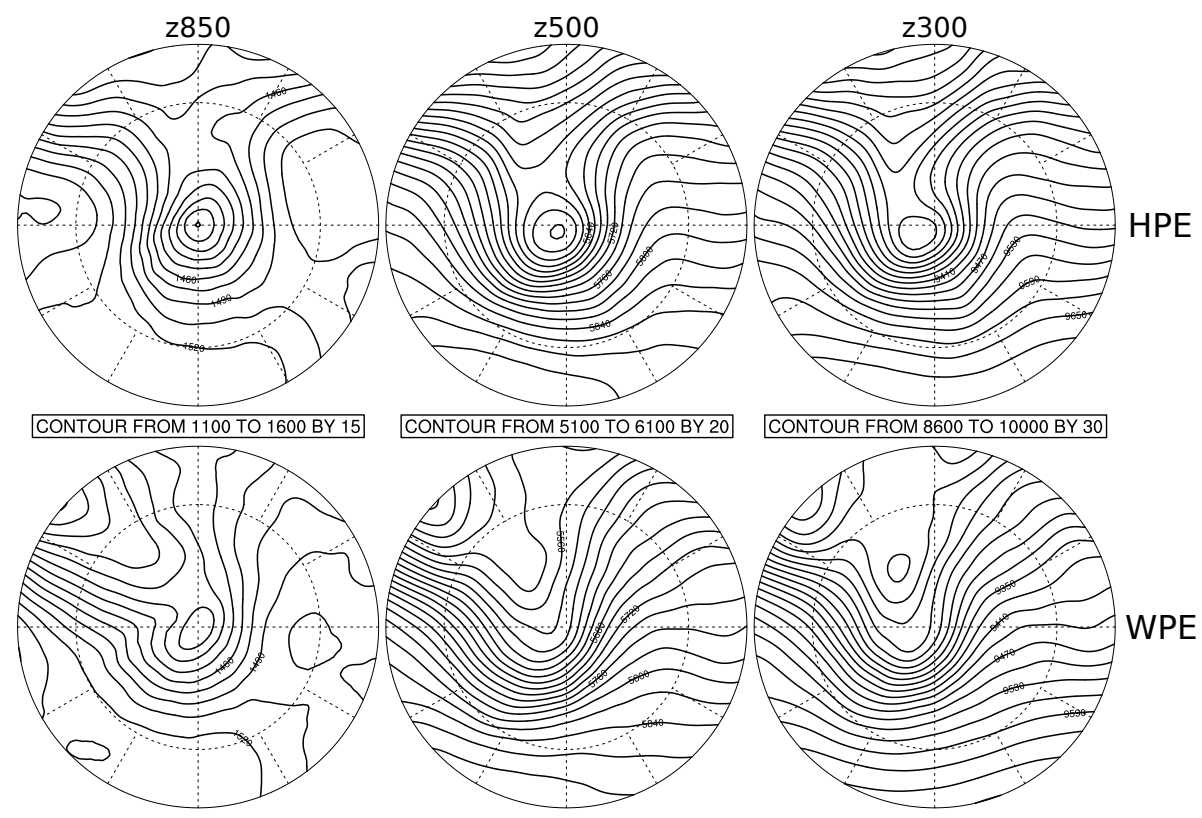

Figure 9. Average geopotential height at $850 \mathrm{hPa}$ (left column panels), $500 \mathrm{hPa}$ (centre column panels) and $300 \mathrm{hPa}$ (right column) for the time step with maximum precipitation of all HPEs (upper row panels) and WPEs (bottom row panels). The distance from the centre of the composite cyclone to the edge is $23^{\circ}$.

tection tool applied in the first step. Nevertheless, there are some important differences. The composites of HPEs exhibit a strong cyclone, as a steep gradient in combination with a deep depression is observed. The fact that the HPEs are triggered by a distinct cyclone is more obvious when considering higher levels, because the depression from the ground extends through the 500 and $300 \mathrm{hPa}$ levels. Another indication for a strong developing cyclone is the westward tilting of the system. This is in contrast with the WPEs, which are induced by a shallow depression. Even though the z850 shows an isolated isobar, this feature is lost at the $500 \mathrm{hPa}$ and appears as a weakened trough at $300 \mathrm{hPa}$ again. Another important feature is detected in the northwest of the WPEs in terms of a depression. This system seems to coalesce with the original depression, which leads to an asymmetric geopotential height gradient on the southern side of the cyclone centre.

The hypothesis of associating a stronger cyclone with HPEs is underlined when analysing the potential vorticity (PV) at the $325 \mathrm{~K}$ potential temperature surface (Fig. 10). For the HPEs, it presents a PV-streamer that is close to a cut-off. This feature is absent in the WPE cases, which show instead a PV maximum in the northwest of the cyclone centre, similar to the situation of the $300 \mathrm{hPa}$ geopotential height field.

The aforementioned differences in the geopotential height fields between the HPEs and WPEs trigger important differences in the wind field in different elevations. Note that the wind fields in different elevations are in good agreement with the vertically integrated moisture flux in regard to direction and relative strength. Figure 6 shows that the HPEs

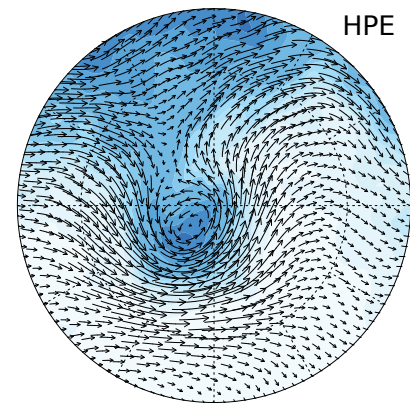

圆

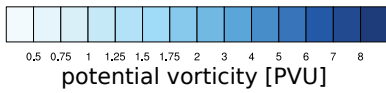

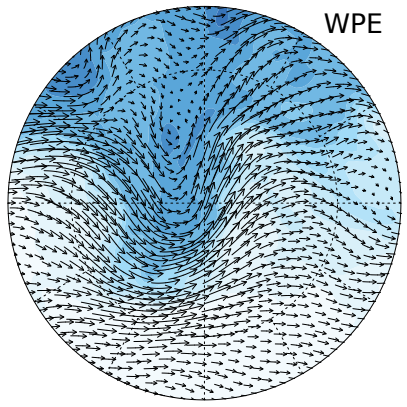

圆

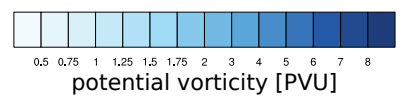

Figure 10. Composites of potential vorticity [PVU, shading] on the $325 \mathrm{~K}$ potential temperature surface at the time step with maximum precipitation of the HPEs (left panel) and the WPEs (right panel). Wind fields are also shown for the $325 \mathrm{~K}$ potential temperature surface (reference vector: $10 \mathrm{~m} \mathrm{~s}^{-1}$ ). The distance from the centre of the composite cyclone to the edge is $23^{\circ}$.

experience strong winds on the southern side of the cyclone centre, transporting air masses directly towards the northwest of the cyclone and out of its influence region. More importantly, rotation around the centre of the cyclone becomes apparent. The same features are also visible on the $325 \mathrm{~K}$ potential temperature surface in Fig. 10, where air masses are transported towards the northeast due to its U-shape, whereas the wind system close to the centre rotates. This rotation is 
highly important for high-impact Vb cyclones (HPEs), as moisture needs to be transported around the Alps to produce orographic lifting along the northern side of the Alps. Hence, orographic precipitation is generated on the northern side of the Alps. This is supported by the fact that a major part of precipitation amounts is actually found on the northeastern side of the Alps (not shown) and thus in the region of interest during the most precipitation intense time step. In contrast, WPEs do not exhibit such a rotating wind field. This is mainly due to the influence of the deeper depression in the northwest of the cyclones appearing at the same time as the WPEs. The strong gradient, which is maintained at the southern side of the actual cyclone centre, results in strong U-shaped wind fields that preclude rotation. Nevertheless, a certain amount of rotation is found above the ground (not shown), which explains the modest amounts of precipitation found in the region of interest. However, the main part of the precipitation can still be detected on the southern side of the Alps (not shown), as orographic lifting occurs there. Thus, the precipitation on the southern side of the Alps is not able to influence the main precipitation area of $\mathrm{Vb}$ cyclones during the most precipitation intense time step.

\section{Discussion and conclusion}

The results concerning the basic climatology of $\mathrm{Vb}$ cyclones show a good agreement with the findings previously reported by Hofstätter and Chimani (2012), i.e. the rareness of Vb cyclones (2.3 $\mathrm{Vb}$ cyclone appearances per year), the peak of $\mathrm{Vb}$ cyclones in spring and a general agreement of the exact appearance of $65 \%$ of all $\mathrm{Vb}$ cyclones compared to Hofstätter and Chimani (2012). As our findings seem to be robust with respect to the applied method, our study goes beyond the statistical climatology introduced by Hofstätter and Chimani (2012) and deepens on the physical mechanisms in order to understand the large variability within the Vb-cyclonetriggered precipitation.

The analysis of the precipitation distribution associated with $\mathrm{Vb}$ cyclones reveals that the cases identified in the extended winter are not able to trigger extreme precipitation. This fact can be explained through the application of the Clausius-Claperyon equation. However, summer cases exhibit larger variability, leading to a number of extreme situations. This motivates a further subclassification of the summer cases using accumulated precipitation over the northern Alpine region and Central Europe as a classification criterion. Although the moisture content in the atmosphere provides a first separation between the extended summer and winter $\mathrm{Vb}$ cyclones through the Clausius-Claperyon equation, it fails to serve as a criterion to separate the 10 WPEs and HPEs in the extended summer, since the inter-case variability is too large. Thus, the moisture content in the atmosphere cannot unambiguously separate the HPEs and WPEs. Also neither the northward moisture flux from the Mediter- ranean Sea nor the southward flux from the Atlantic can succeed in disentangling the different behaviour of WPEs and HPEs. The fact that neither the Mediterranean nor the Atlantic Sea are exclusively responsible for the precipitation brings us to the conclusion that various moisture sources contribute to precipitation in $\mathrm{Vb}$ events. This result is consistent with previous findings reported by Stohl and James (2004), James et al. (2004) and Sodemann et al. (2009) for the onein-a-century flood in August 2002. The large amount of possible moisture source combinations and the various moisture patterns that are associated to the $\mathrm{Vb}$ cyclones enable us to conclude that the moisture content and source strongly depend on a case-to-case basis and preclude obtaining general conclusions.

In contrast, the variables associated to the large-scale dynamics, i.e. geopotential height and PV at the potential temperature level $325 \mathrm{~K}$, allow a meaningful categorisation of the HPEs and WPEs. The average geopotential height field in HPEs shows a distinct cut-off low pressure system extending over the whole atmosphere. Additionally, PV shows a PV-streamer close to cut-off. These two features trigger a vortex that can be traced in the wind fields. These fields suggest that precipitation is triggered by a northerly Alpine inflow. Thus, most of the precipitation falls on the northern to northeastern side of the Alps. Similar situations (pivoting cut-off) have been found by Stucki et al. (2012) in the context of past extreme floods in Switzerland. Hereby the cutoff low is located over the Adriatic Sea and is near-stationary due to blocking surface highs, located over western and eastern Europe. Also Zängl (2004) identified the orographic enhancement as an important trigger for the high precipitation records in August 2002. The WPEs in contrary are only associated with weak low pressure systems that do not elongate through various atmospheric layers. Also PV reveals only an initial state of a PV-streamer. Hence, there is no vortex visible in the wind fields. In the case of the WPEs, we conclude that the Alpine inflow takes place at the southern or southeastern side of the Alps, which is supported by the mostly southerly located precipitation amounts. These features are similar to the "Canarian Trough" described by Stucki et al. (2012) in association with past extreme floods in Switzerland. These cyclones are strongly influenced by a low over Brittany and thus show a southwesterly flow (Stucki et al., 2012). The same is true for the WPEs, which are strongly influenced by a low in the northeast of their cyclone centres. Additionally it must be kept in mind that cyclone development in the vicinity of the Alps is a very complex problem. Due to strong nongeostrophic secondary flows, the appearance of near-surface closed isobars is not sufficient to produce cyclonic vorticity (Speranza, 1975). Thus, although WPE can be detected as closed isobars, i.e. cyclones, these cyclones are shallow and show no real meteorological impact, which stands in clear contrast to the cyclones associated with HPE.

The fact that unlike humidity, the large-scale dynamic behaviour of the atmosphere allows a clear differentiation be- 
tween the HPEs and WPEs, leads us to the conclusion that the thermodynamic state of the atmosphere only plays a secondary role in triggering heavy precipitation associated to $\mathrm{Vb}$ events. These findings have important implications for a future climate change. On the one hand, an increased moisture amount is projected in the atmosphere as a response to the increase in temperature with a changing climate (again associated to the Clausius-Claperyon equation). Hence, an increase in precipitation amounts can be expected in principle in the future. This argument is supported by Zappa et al. (2014) stating that an increase in atmospheric moisture content is responsible for an increased cyclone precipitation intensity in the northern Mediterranean. On the other hand, Pal et al. (2004), Yin (2005), Giorgi and Lionello (2008) and Raible et al. (2010) argue that shifts in the cyclone track, and thus changes in the more important dynamical part of a $\mathrm{Vb} c y-$ clone, are expected under a future climate. In particular, the former studies project a poleward shift of the storm track in a future climate, while Woollings et al. (2012) expect an eastward extension of the storm track towards Europe. These projections about the changing behaviour of the storm track in the future suggests that the phenomenon $\mathrm{Vb}$ cyclone could become even rarer if either of the two shifts occur. Combining these two arguments, it can be expected that $\mathrm{Vb}$ cyclones would happen more seldom, but with an increased intensity in precipitation. Nissen et al. (2013) point in the same direction in a study on $\mathrm{Vb}$ cyclones. However, this hypothesis is associated with a large amount of uncertainty, and a more precise assessment of the future behaviour of $\mathrm{Vb}$ events and their related impacts cannot be done with the evidence exposed in this analysis. Thus, more research on the large-scale dynamic changes of different $\mathrm{Vb}$ cyclone subcategories under a future climate is needed to fully understand the changes in precipitation amounts and frequency of $\mathrm{Vb}$ cyclones.

Even though it is possible to find a reason for the high variability in $\mathrm{Vb}$ cyclone triggered precipitation amounts, the exact triggering mechanism for precipitation cannot be found using the coarse resolution of ERA-Interim. This is especially true in the Alpine region, where the coarse resolution is a strong limiting factor of ERA-Interim. As the $\mathrm{Vb}$ cyclones are phenomena, which strongly depend on mountains, more insights could be gained using regional modelling. Dynamical downscaling will not only improve the spatial resolution, but also the temporal resolution. Such a higher resolved data set will allow a closer look into thermodynamics, while an increased temporal resolution can provide additional information on dynamics (Muskulus and Jacob, 2005). Planned sensitivity studies on SST over different locations and soil moisture in the regional model framework will allow us to gain a deeper insight on the moisture source and thus on thermodynamics in several single $\mathrm{Vb}$ events. Furthermore, the fine resolution allows distinguishing the mechanisms that trigger a $\mathrm{Vb}$ cyclone with and without meteorological impact. Additionally the regional model framework can simulate the diabatic heating processes and thus PV development or the presence of warm conveyor belts during the cyclones life cycle. Thus, future studies will consider the re-evaluation of the $\mathrm{Vb}$ cyclone climatology based on high-regional downscaling products, as well as direct assessments of the evolution $\mathrm{Vb}$ events through climate simulations.

Acknowledgements. The authors are grateful for the funding provided by the Dr. Alfred Bretscher-Fonds für Klima- und Luftverschmutzungsforschung. Thanks are also due to the support provided by the Oeschger Centre for Climate Change Research and the Mobiliar lab for climate risks and natural hazards (Mobilab). The ERA-Interim reanalysis data were provided by the ECMWF. Furthermore, we acknowledge the E-OBS data set from the EU-FP6 project ENSEMBLES (http://ensembles-eu.metoffice.com) and the data providers in the ECA\&D project (http://www.ecad.eu). Thanks are due to the two referees J. G. Pinto and A. Speranza for their constructive comments that helped to improve the manuscript substantially.

Edited by: V. Lucarini

\section{References}

Bengtsson, L., Hodges, K. I., Esch, M., Keenlyside, N., Kornblueh, L., Luo, J.-J., and Yamagata, T.: How may tropical cyclones change in a warmer climate?, Tellus A, 59, 539-561, doi:10.1111/j.1600-0870.2007.00251.x, 2007.

Beniston, M.: August 2005 intense rainfall event in Switzerland: Not necessarily an analog for strong convective events in a greenhouse climate, Geophys. Res. Lett., 33, L05701, doi:10.1029/2005GL025573, 2006.

Blender, R., Fraedrich, K., and Lunkeit, F.: Identification of cyclone-track regimes in the North Atlantic, Q. J. Roy. Meteorol. Soc., 123, 727-741, doi:10.1002/qj.49712353910, 1997.

Dee, D. P., Uppala, S. M., Simmons, A. J., Berrisford, P., Poli, P., Kobayashi, S., Andrae, U., Balmaseda, M. A., Balsamo, G., Bauer, P., Bechtold, P., Beljaars, A. C. M., van de Berg, L., Bidlot, J., Bormann, N., Delsol, C., Dragani, R., Fuentes, M., Geer, A. J., Haimberger, L., Healy, S. B., Hersbach, H., Hólm, E. V., Isaksen, L., Kållberg, P., Köhler, M., Matricardi, M., McNally, A. P., Monge-Sanz, B. M., Morcrette, J.-J., Park, B.-K., Peubey, C., de Rosnay, P., Tavolato, C., Thëpaut, J.-N., and Vitart, F.: The ERA-Interim reanalysis: Configuration and performance of the data assimilation system, Q. J. Roy. Meteorol. Soc., 137, 553597, doi:10.1002/qj.828, 2011.

Donat, M. G., Pardowitz, T., Leckebusch, G. C., Ulbrich, U., and Burghoff, O.: High-resolution refinement of a storm loss model and estimation of return periods of loss-intensive storms over Germany, Nat. Hazards Earth Syst. Sci., 11, 2821-2833, doi:10.5194/nhess-11-2821-2011, 2011.

Fink, A. H., Pohle, S., Pinto, J. G., and Knippertz, P.: Diagnosing the influence of diabatic processes on the explosive deepening of extratropical cyclones, Geophys. Res. Lett., 39, L07803, doi:10.1029/2012GL051025, 2012.

Fricke, W. and Kaminski, U.: Ist die Zunahme von Starkniederschlägen auf veränderte Wetterlagen zurückzuführen, GAW Brief des Deutschen Wetterdienstes, DWD, 12 pp., 
http://www.dwd.de/bvbw/generator/DWDWWW/Content/ Forschung/FEHP/GAW/DL/GAW__BRIEFE/gaw__brief_ _012_de__pdf,templateId=raw, property=publicationFile.pdf/ gaw_brief_012_de_pdf.pdf (last access: August 2015), 2002.

Gao, X., Pal, J. S., and Giorgi, F.: Projected changes in mean and extreme precipitation over the Mediterranean region from a high resolution double nested RCM simulation, Geophys. Res. Lett., 33, L03706, doi:10.1029/2005GL024954, 2006.

Giorgi, F.: Climate change hot-spots, Geophys. Res. Lett., 33, L08707, doi:10.1029/2006GL025734, 2006.

Giorgi, F. and Lionello, P.: Climate change projections for the Mediterranean region, Global Planet. Change, 63, 90-104, doi:10.1016/j.gloplacha.2007.09.005, 2008.

Grams, C. M., Binder, H., Pfahl, S., Piaget, N., and Wernli, H.: Atmospheric processes triggering the central European floods in June 2013, Nat. Hazards Earth Syst. Sci., 14, 1691-1702, doi:10.5194/nhess-14-1691-2014, 2014.

Grazzini, F. and van der Grijn, G.: Central European floods during summer 2002, ECMWF Newslett., 96, 18-28, 2002.

Gómez-Navarro, J. J., Montávez, J. P., Jerez, S., Jiménez-Guerrero, P., and Zorita, E.: What is the role of the observational dataset in the evaluation and scoring of climate models?, Geophys. Res. Lett., 39, L24701, doi:10.1029/2012GL054206, 2012.

Haylock, M. R., Hofstra, N., Klein Tank, A. M. G., Klok, E. J., Jones, P. D., and New, M.: A European daily highresolution gridded data set of surface temperature and precipitation for 1950-2006, J. Geophys. Res.-Atmos., 113, D20119, doi:10.1029/2008JD010201, 2008.

Held, H., Gerstengarbe, F.-W., Pardowitz, T., Pinto, J. G., Ulbrich, U., Born, K., Donat, M. G., Karremann, M. K., Leckebusch, G. C., Ludwig, P., Nissen, K. M., Österle, H., Prahl, B. F., Werner, P. C., Befort, D. J., and Burghoff, O.: Projections of global warming-induced impacts on winter storm losses in the German private household sector, Climatic Change, 121, 195207, doi:10.1007/s10584-013-0872-7, 2013.

Hofstätter, M. and Chimani, B.: Van Bebber's cyclone tracks at $700 \mathrm{hPa}$ in the Eastern Alps for 1961-2002 and their comparison to circulation type classifications, Meteorol. Z., 21, 459-473, doi:10.1127/0941-2948/2012/0473, 2012.

Hofstra, N., Haylock, M., New, M., and Jones, P. D.: Testing E-OBS European high-resolution gridded data set of daily precipitation and surface temperature, J. Geophys. Res.-Atmos., 114, D21101, doi:10.1029/2009JD011799, 2009.

IPCC-AR4: The physical science basis, in: Contribution of Working Group I to the Fourth Assessment Report of the Intergovernmental Panel on Climate Change, edited by: Solomon, S., Qin, D., Manning, M., Chen, Z., Marquis, M., Averyt, K. B., Tignor, M., and Miller, H. L., Cambridge University Press, Cambridge, UK, and New York, NY, USA, 2007.

IPCC-SREX: Managing the Risks of Extreme Events and Disasters to Advance Climate Change Adaptation, in: A Special Report of Working Groups I and II of the Intergovernmental Panel on Climate Change, edited by: Field, C. B., Barros, V., Stocker, T. F., Qin, D., Dokken, D. J., Ebi, K. L., Mastrandrea, M. D., Mach, K. J., Plattner, G.-K., Allen, S. K., Tignor, M., and Midgley, P. M., Cambridge University Press, Cambridge, UK, and New York, NY, USA, 2012.

James, P., Stohl, A., Spichtinger, N., Eckhardt, S., and Forster, C.: Climatological aspects of the extreme European rainfall of $\mathrm{Au}-$ gust 2002 and a trajectory method for estimating the associated evaporative source regions, Nat. Hazards Earth Syst. Sci., 4, 733746, doi:10.5194/nhess-4-733-2004, 2004.

Kaspar, M. and Müller, M.: Selection of historic heavy large-scale rainfall events in the Czech Republic, Nat. Hazards Earth Syst. Sci., 8, 1359-1367, doi:10.5194/nhess-8-1359-2008, 2008.

Köppen, W.: Die Zugstrassen der barometrischen Minima in Europa und auf dem nordatlantischen Ocean und ihr Einfluss auf Wind und Wetter bei uns, Mittheilungen der Geographischen Gesellschaft in Hamburg, 1, 76-97, 1881.

Kron, W., Steuer, M., Löw, P., and Wirtz, A.: How to deal properly with a natural catastrophe database - analysis of flood losses, Nat. Hazards Earth Syst. Sci., 12, 535-550, doi:10.5194/nhess12-535-2012, 2012.

Kundzewicz, Z. W., Ulbrich, U., Brücher, T., Graczyk, D., Krüger, A., Leckebusch, G. C., Menzel, L., Pinskwar, I., Radziejewski, M., and Szwed, M.: Summer Floods in Central Europe - Climate Change Track?, Nat. Hazards, 36, 165-189, doi:10.1007/s11069004-4547-6, 2005.

Lionello, P., Dalan, F., and Elvini, E.: Cyclones in the Mediterranean region: the present and the doubled $\mathrm{CO}_{2}$ climate scenarios, Clim. Res., 22, 147-159, doi:10.3354/cr022147, 2002.

Lionello, P., Trigo, I. F., Gil, V., Liberato, M. L. R., Nissen, K., Pinto, J. G., Raible, C. C., Reale, M., Tanzarella, A., Trigo, R. M., Ulbrich, S., and Ulbrich, U.: Objective Climatology of Cyclones in the Mediterranean Region: a consensus view among methods with different system identification and tracking criteria, Tellus, in preparation, 2015.

Martius, O., Zenklusen, E., Schwierz, C., and Davies, H. C.: Episodes of alpine heavy precipitation with an overlying elongated stratospheric intrusion: a climatology, Int. J. Climatol., 26, 1149-1164, doi:10.1002/joc.1295, 2006.

Mudelsee, M., Börngen, M., Tetzlaff, G., and Grünewald, U.: Extreme floods in Central Europe over the past 500 years: Role of cyclone pathway "Zugstrasse Vb", J. Geophys. Res.-Atmos., 109, D23101, doi:10.1029/2004JD005034, 2004.

Muskulus, M. and Jacob, D.: Tracking cyclones in regional model data: The future of Mediterranean storms, Adv. Geosci., 2, 1319, doi:10.5194/adgeo-2-13-2005, 2005.

Neu, U., Akperov, M. G., Bellenbaum, N., Benestad, R., Blender, R., Caballero, R., Cocozza, A., Dacre, H. F., Feng, Y., Fraedrich, K., Grieger, J., Gulev, S., Hanley, J., Hewson, T., Inatsu, M., Keay, K., Kew, S. F., Kindem, I., Leckebusch, G. C., Liberato, M. L. R., Lionello, P., Mokhov, I. I., Pinto, J. G., Raible, C. C., Reale, M., Rudeva, I., Schuster, M., Simmonds, I., Sinclair, M., Sprenger, M., Tilinina, N. D., Trigo, I. F., Ulbrich, S., Ulbrich, U., Wang, X. L., and Wernli, H.: IMILAST: A community effort to intercompare extratropical cyclone detection and tracking algorithms, B. Am. Meteorol. Soc., 94, 529-547, doi:10.1175/BAMS-D-11-00154.1, 2013.

Nissen, K. M., Ulbrich, U., and Leckebusch, G. C.: Vb cyclones and associated rainfall extremes over Central Europe under present day and climate change conditions, Meteorol. Z., 22, 649-660, doi:10.1127/0941-2948/2013/0514, 2013.

Nissen, K. M., Leckebusch, G. C., Pinto, J. G., and Ulbrich, U.: Mediterranean cyclones and windstorms in a changing climate, Reg. Environ. Change, 14, 1873-1890, doi:10.1007/s10113-0120400-8, 2014. 
Pal, J. S., Giorgi, F., and Bi, X.: Consistency of recent European summer precipitation trends and extremes with future regional climate projections, Geophys. Res. Lett., 31, L13202, doi:10.1029/2004GL019836, 2004.

Pinto, J. G., Spangehl, T., Ulbrich, U., and Speth, P.: Assessment of winter cyclone activity in a transient ECHAM4-OPYC3 GHG experiment, Meteorol. Z., 15, 279-291, doi:10.1127/09412948/2006/0128, 2006.

Pinto, J. G., Ulbrich, S., Parodi, A., Rudari, R., Boni, G., and Ulbrich, U.: Identification and ranking of extraordinary rainfall events over Northwest Italy: The role of Atlantic moisture, J. Geophys. Res.-Atmos., 118, 2085-2097, doi:10.1002/jgrd.50179, 2013.

Raible, C. C.: On the relation between extremes of midlatitude cyclones and the atmospheric circulation using ERA40, Geophys. Res. Lett., 34, L07703, doi:10.1029/2006GL029084, 2007.

Raible, C. C., Della-Marta, P. M., Schwierz, C., Wernli, H., and Blender, R.: Northern Hemisphere extratropical cyclones: A comparison of detection and tracking methods and different reanalyses, Mon. Weather Rev., 136, 880-897, doi:10.1175/2007MWR2143.1, 2008.

Raible, C. C., Ziv, B., Saaroni, H., and Wild, M.: Winter synopticscale variability over the Mediterranean Basin under future climate conditions as simulated by the ECHAM5, Clim. Dynam., 35, 473-488, doi:10.1007/s00382-009-0678-5, 2010.

Sodemann, H. and Zubler, E.: Seasonal and inter-annual variability of the moisture sources for Alpine precipitation during 19952002, Int. J. Climatol., 30, 947-961, doi:10.1002/joc.1932, 2010.

Sodemann, H., Wernli, H., and Schwierz, C.: Sources of water vapour contributing to the Elbe flood in August 2002 - A tagging study in a mesoscale model, Q. J. Roy. Meteorol. Soc., 135, 205-223, doi:10.1002/qj.374, 2009.

Speranza, A.: The formation of baric depressions near the Alps, Ann. Geophys., 28, 177-217, doi:10.4401/ag-4898, 1975.

Stohl, A. and James, P.: A Lagrangian analysis of the atmospheric branch of the global water cycle, Part I: Method description, validation, and demonstration for the August 2002 flooding in Central Europe, J. Hydrometeorol., 5, 656-678, doi:10.1175/15257541(2004)005<0656:ALAOTA>2.0.CO;2, 2004.

Stucki, P., Rickli, R., Brönnimann, S., Martius, O., Wanner, H., Grebner, D., and Luterbacher, J.: Weather patterns and hydro-climatological precursors of extreme floods in Switzerland since 1868, Meteorol. Z., 21, 531-550, doi:10.1127/09412948/2012/368, 2012.
Stucki, P., Brönnimann, S., Martius, O., Welker, C., Imhof, M., von Wattenwyl, N., and Philipp, N.: A catalog of high-impact windstorms in Switzerland since 1859, Nat. Hazards Earth Syst. Sci., 14, 2867-2882, doi:10.5194/nhess-14-2867-2014, 2014.

Trigo, I. F., Davies, T. D., and Bigg, G. R.: Objective climatology of cyclones in the Mediterranean region, J. Climate, 12, 1685-1696, doi:10.1175/1520-0442(1999)012<1685:OCOCIT>2.0.CO;2, 1999.

Ulbrich, U., Brücher, T., Fink, A. H., Leckebusch, G. C., Krüger, A., and Pinto, J. G.: The central European floods of August 2002: Part 1 - Rainfall periods and flood development, Weather, 58, 371-377, doi:10.1256/wea.61.03A, 2003a.

Ulbrich, U., Brücher, T., Fink, A. H., Leckebusch, G. C., Krüger, A., and Pinto, J. G.: The central European floods of August 2002: Part 2 - Synoptic causes and considerations with respect to climatic change, Weather, 58, 434-442, doi:10.1256/wea.61.03B, 2003b.

Van Bebber, W.: Die Zugstrassen der barometrischen Minima nach den Bahnenkarten der deutschen Seewarte für den Zeitraum 1875-1890, Meteorol. Z., 8, 361-366, 1891.

Winschall, A., Pfahl, S., Sodemann, H., and Wernli, H.: Impact of North Atlantic evaporation hot spots on southern Alpine heavy precipitation events, Q. J. Roy. Meteorol. Soc., 138, 1245-1258, doi:10.1002/qj.987, 2012.

Woollings, T., Gregory, J. M., Pinto, J. G., Reyers, M., and Brayshaw, D. J.: Response of the North Atlantic storm track to climate change shaped by ocean-atmosphere coupling, Nat. Geosci., 5, 313-317, doi:10.1038/ngeo1438, 2012.

Yin, J. H.: A consistent poleward shift of the storm tracks in simulations of 21st century climate, Geophys. Res. Lett., 32, L18701, doi:10.1029/2005GL023684, 2005.

Zängl, G.: Numerical simulations of the 12-13 August 2002 flooding event in eastern Germany, Q. J. Roy. Meteorol. Soc., 130, 1921-1940, doi:10.1256/qj.03.152, 2004.

Zappa, G., Hawcroft, M. K., Shaffrey, L., Black, E., and Brayshaw, D. J.: Extratropical cyclones and the projected decline of winter Mediterranean precipitation in the CMIP5 models, Clim. Dynam., doi:10.1007/s00382-014-2426-8, in press, 2014. 